\title{
ONTWIKKELING EN PERSPEKTIEF IN DIE SUID-AFRIKAANSE INDUSTRIE
}

\section{Ontstaan, groei en ontwikkeling.}

Die eerste nywerheidsontwikkeling in Suid-Afrika was onvermydelik gekoppel aan die landbou-, die wyn- en verwante nywerhede in die Kaap en die suikernywerheid in Natal. In beide gevalle het dié nywerhede 'n belangrike bydrae gemaak in die globale ontwikkeling in ons land, en in die toekoms sal dit steeds 'n belangrike bydrae lewer.

Die derde belangrike omwenteling het gekom rondom ons mynwese d.i. die ontginning van diamante en steenkool maar veral die ontginning, suiwering en veredeling van goud. Waar eersgenoemde twee minerale hoofsaaklik 'n delf- en mynproses was, wat op 'n redelike vlak diepte uitgevoer is, is die ontginning en reduksie van goud ' $n$ ingewikkelde proses wat beide ontwikkeling van die mynwese sowel as 'n belang. rike stimulus vir die chemiese en ingenieursbedrywe verskaf het.

Die produksie van goud en steenkool het groot hoeveelhede plofstof benodig en hoewel dit oorspronklik ingevoer is, het die hoeveelhede wat gebruik is, so 'n omvang aangeneem dat daar teen 1896 besluit is om dit plaaslik te vervaardig, en dit het dadelik die gevolg gehad dat 'n aktiewe nukleus van 'n kerngesonde chemiese nywerheid gelê is - een nywerheid wat baie min van die skokke van depressies, ekonomiese terugslae en tekorte gevoel het en oor die afgelope sewentig jaar snel gegroei het.

Met die groei en ontwikkeling van die mynwese, groter gebruik van meganisasie, die grawe van dieper skagte en die algemene vooruitgang op tegnologiese gebied, is ook die groei en ontwikkeling van die ingenieurs- en verwante bedrywe gestimuleer, en het die ontwikkeling van hierdie sekondêre nywerhede so snel toegeneem dat Suid-Afrika, wat mynwese aanbetref, uitgetroon het as wêreldleiers en selfs vandag word van ons myntoerusting na ander dele van die wêreld uitgevoer.

Daar moet egter duidelik gekonstateer word dat ons feitlik die hele tyd in die skaduwee van moeder Engeland geskuil het, en hierdie gemaklike posisie was seer sekerlik nie die heel beste stimuleermiddel vir die vestiging en ontwikkeling 
van grootskaalse nywerhede nie en die groei kon alleen so vinnig plaasvind as wat die lengte van haar rokspante en die plaaslike gebrek aan lojaliteit dit toegelaat het. Tewens, as ons 'n analise maak van sekere feite, statistieke en veral 'n gebrek aan 'n konstante groei in ons nywerheidsontwikkeling, kan dit teruggevoer word na een enkele grondoorsaak en d.i. dat dit inbreuk sou maak op die uitvoere van die Moeder na die "dominion". 'n Faktor wat ook nie uit die oog verloor moet word nie, is die rol wat agente en agentskappe van oorsese produkte in Suid-Afrika gespeel het. Baie van die voorspooksels en teenargumente wat nywerheidsontwikkeling in Suid-Afrika gestrem het, was uit dié bron afkomstig.

Ons kan egter aanneem dat die eerste tekortkominge van ons nywerheidsstandaard gedurende Wêreldoorlog $I$ aan die lig gekom het, maar met 'n "lojale" regering aan bewind tot 1924, is sistematiese ontwikkeling op dié gebied steeds op die lange baan geskuif.

Die einde van die "laissez faire-beleid" en 'n gedetermineerde, positiewe rigting is egter ingeslaan van 1924 af, toe die Pakt-regering aan bewind gekom het. Sy eerste groot toets het gekom met die vestiging van Yskor, ${ }^{1}$ ) en die stryd wat die vestiging van hierdie nywerheid vooraf gegaan het verskaf amusante leesstof as $u$ miskien ' $n$ vry aand wil geniet - ' $n$ bietjie verbeeldingskrag en 'n snelle leestempo (want daar is voorwaar baie gepraat) is inderdaad 'n ,silence" film uit hierdie bewoë tydperk en die moed, durf en deursettingsvermoë van die leiers van die destydse regering verdien beslis 'n monument, want as net maar een van hierdie nywerheidsnagmerries wat deur die opposisie opgediep is, waarheid geword het, sou die nawerking hiervan nog lank gehoor word. Maar gelukkig het die vestiging van die nywerheid genl. Smuts in staat gestel om gedurende Wêreldoorlog II sy NoordAfrikaanse offensief sonder enige staalbekommernisse deur te voer en kon hy selfs Suid-Afrikaanse staal aan ander lande aanbied.

Die depressiejare, die jare wat Wêreldoorlog II voorafgegaan het, en met 'n "lojale" regering aan bewind, word gekenmerk deur 'n stadige groei maar veral 'n gebrek aan duidelike beplanning van nywerheidsontwikkeling in SuidAfrika.

Twee faktore het hiertoe bygedra: 
1. 'n „Lojale" regering wat net beplan het soos dit die sak van moeder Engeland gepas het.

2. Dit het die gevolg gehad dat nywerheidontwikkeling aan die kus voorkeur gekry het, omdat ons soveel as moontlik ingevoer het en alleen die primitiefste ware uitgevoer het.

Waar sou ons land nie vandag gestaan het as ons ons motornywerheid gekoppel het aan ons binnelandse staalnywerheid. Dit sou gieterye, vervaardiging van onderdele, ingenieursbedrywe, elektriese toerusting ens. op groot skaal tot gevolg gehad het. In teenstelling hiermee het ons vir 'n lang tyd toegelaat dat die motor in stukke ingevoer en aan die kus gemonteer word.

Met die uitbreek van Wêreldoorlog II het die aanvraag na staal en yster sulke afmetings aangeneem dat die Staalwerke van Pretoria net nie langer aan die aanvraag kon voldoen nie, en verder het vooruitramings en skattings aangetoon dat 'n tweede staalnywerheid nou noodsaaklik geword het, en dit het uiteindelik gekulmineer in die vestiging van 'n multi-miljoen-staalnywerheid in die Transvaalse Hoëveld, en die beplanning van 'n splinternuwe stadskompleks - Vanderbijlpark - het spoedig daaromheen gepaddastoel.

Wêreldoorlog II het egter 'n baie belangrike tendens aan die lig gebring, naamlik 'n groeiende gevoel van selfstandigheid en 'n besef dat ons iets moes doen om die kritieke behoeftes wat in dié tydperk gevoel is die hoof te bied, toe selfs rolle latrinepapier „ship them flat" verpak is om skeepsruimte te bespaar.

\section{Groei ná Wêreldoorlog II.}

Die finale breuk het reeds duidelik geword in die tydperk 1945 tot 1948 toe ons land die invloed begin voel het van die tekorte aan invoervaluta en dit feitlik onmoontlik geword het om 'n balans te handhaaf.

'n Finale beslissing moes egter uitbly tot 1948, toe 'n nuwe regering aan bewind gekom het' wat kortmette gemaak het met baie van ons ekonomiese probleme, deur invoerbeheer toe te pas wat die finale rokspante met die oorsese nywerheidsmoeder afgekap en 'n eie nywerheidsklimaat geskep het, wat inderdaad ' $n$ nywerheidsontploffing bewerkstellig het.

Hoewel die beginsels wat gehandhaaf is reg en korrek 
was, was ons plasing van nywerhede nie altyd korrek nie.

Op politieke gebied het ons gepraat van selfstandige ontwikkeling van die verskillende volksgroepe, uitbouiing van die Bantoetuislande ens., tog het die getal Bantoes wat ons toegelaat het om in suiwer blanke gebiede en veral in ons vyf grootste nywerheidsgebiede t.w. die Rand, Pretoria, Durban, Port Elizabeth en die Kaap in te trek, 'n skrille teenstelling gevorm met ons politieke leerstellings. In Die Transvaler $^{2}$ ) van 7 Sept. 1966 word die volgende syfers in 'n brief aangetoon om hierdie stelling te verduidelik:

\section{Sensus van stedelike bevolkingsgroepe}

\begin{tabular}{lrrrrr}
$\begin{array}{l}\text { Bevolkings- } \\
\text { groep }\end{array}$ & 1921 & 1936 & 1946 & \multicolumn{1}{c}{1961} & \multicolumn{1}{c}{1960} \\
Blankes & 847,508 & $1,360,970$ & $1,768,546$ & $2,088,551$ & $2,581,731$ \\
Asiate & 51,209 & 157,425 & 203,271 & 284,663 & 397,101 \\
Kleurlinge & 249,968 & 439,972 & 565,331 & 730,577 & $1,031,063$ \\
Bantoe & 587,000 & $1,245,682$ & $1,856,028$ & $2,390,586$ & $3,471,233$ \\
\multicolumn{7}{c}{} \\
$\begin{array}{l}\text { Bevolkings- } \\
\quad \text { Totale toename }\end{array}$ & Totale toename & Totale toename \\
$\quad 1936$ tot 1946 & 1946 tot 1951 & 1951 tot 1960 \\
Blankes & $407,572(29.9 \%)$ & $320,005(18.1 \%)$ & 492,180 & $(23.5 \%)$ \\
Asiate & $45,746(29.1 \%)$ & $81,392(40.0 \%)$ & $112,438(49.0 \%)$ \\
Kleurlinge & $125,359(28.5 \%)$ & $65,246(11.7 \%)$ & 300,486 & $(41.1 \%)$ \\
Bantoe & $610,346(48.9 \%)$ & $434,558(23.4 \%)$ & $1,080,647(44.7 \%)$
\end{tabular}

„Dit gee 'n gemiddelde toename van stedelike Bantoes in die tydperk 1951-1960 van 120,072 per jaar of 10,006 per maand. Hiervolgens vermeerder die aantal Bantoes in ons stadsgebiede met gemiddeld 330 per dag teenoor 'n vermeerdering van net 150 blankes per dag! Dit beteken dat die persentasie-aandeel van die blankes in die totale stadsbevolking, immigrasie ten spyt, met haas elke volkstelling kleiner sal word.

„Die groei van die Bantoestadsbevolking is nie meer afhanklik van stadwaartse migrasie uit landelike gebiede nie, aangesien die groot Bantoevrouebevolking in die stadsgebiede stabiliteit en 'n groeikrag vir dié bevolking in die hand werk.

„Dit is dus nie te verwonder nie dat die Bantoestadsbevolking met die 1946-sensus meer was as die blanke stedelinge. In die 1960-sensus was daar bykans soveel Bantoes in die 
stadsgebiede as wat daar blankes en Kleurlinge saam was.

„Enkele syfers oor die aantal Bantoes in 1960 in ons vernaamste metropolitaanse streke bring dié feit duidelik onder oë: Bloemfontein $(76,000)$; Germiston $(121,000)$; Port Elizabeth $(123,000)$; Pretoria $(200,000)$; Durban $(222,000)$; en Johannesburg $(651,000) . "$

Hierdie toestand spruit voort uit die feit dat ons toegelaat het dat die arbeidsintensiewe sekondêre nywerhede tot 'n groot mate onverhinderd kon voortgaan om in die genoemde gebiede uit te brei terwyl nog ander groot nywerhede in die gebiede gevestig is of die reeds bestaande aansienlik uitgebrei is.

Die grootste flater is seker die geweldige ontwikkeling wat plaasgevind het in die groter "Vaaldriehoek" wat Sasolburg, Vereeniging, die Rand, Pretoria en die omliggende goudmyne insluit. Ek wil graag 'n paar belangrikste uitbreidings hier aanstip:

1. Uitbreidings in ons staalproduksie by Pretoria en Vanderbijlpark wat onwillekeurig die gevolg gehad het dat die verwante ingenieurs- en ander sekondêre nywerhede hulle ook in die omgewing moes vestig en uitbrei.

2. Die vestiging van Sasol en die uitbouing van hierdie nuwe nywerheidskompleks met al sy neweprodukte het verdere uitbreidings gestimuleer, hoewel Sasol self natuurlik 'n kapitaal-intensiewe en 'n oorwegend blanke nywerheid is.

3. Die neiging van nyweraars en beplanners om koste te definieer in terme van die posisie soos dit in die metropolitaanse gebiede is.

Hierdie laaste faktor het seker een van die belangrikste bydraes gelewer tot die konsentrasie in die gebied en die onvermoë van baie beplanners om na ander moontlike plekke te kyk, want vandag omvat die groot Vaaldriehoek die grootste mynbou- en nywerheidsgebied van Suid-Afrika. Hierdie gebied verskaf werk aan ongeveer die helfte van die nywerheidswerkers van die land, verskaf ongeveer die helfte van die bruto-opbrengs van die nywerhede en volgens skatting dra dit ook die helfte by van die Bruto Nasionale Inkome ("Gross National Product") en word ook meer as die helfte van die belastings hier geïn.

Sedert 1948 word daar op politieke gebied baie aandag gegee aan die ontwikkeling van die grensgebiede en vestiging 
van nywerhede daar, maar hierdie beleid het eers momentum ontwikkel teen ongeveer 1960, toe inderdaad daartoe oorgegaan is om finansiële hulp en belastingverligting vir nywerhede in die gebiede toe te staan.

Die gemiddelde nyweraar het egter nog steeds geargumenteer dat dit voordeliger is om by ' $n$ bestaande nywerheid in die metropolitaanse gebied uit te brei, terwyl die produksiekoste daar dan ook laer sou wees. Dit word kortliks aangedui in die volgende tabelle: Vergelyking tussen die koste van 'n geïntegreerde en 'n
grensnywerheid

Geïtegreerde nywerheid

Eiendom

Koste van aanleg

Addisionele dienste

Ander fasiliteite

Stoorruimte

Afvalhantering

Ander koste

\begin{tabular}{rr}
\hline$, 150,000$ & 4,000 \\
140,000 & $3,225,000$ \\
10,000 & 240,000 \\
200,000 & 200,000 \\
200,000 & 300,000 \\
80,000 & 200,000 \\
\hline R3,780,000 & 140,000 \\
\cline { 2 - 2 } & R4,309,000
\end{tabular}

Grens-

nywerheid

4,000

200,000

300,000

200,000

40,000

R4,309,000

Vergelyking tussen produksiekoste per ton produk

$\begin{array}{lcc} & \begin{array}{c}\text { Geintegreerde } \\ \text { nywerheid }\end{array} & \begin{array}{c}\text { Grens- } \\ \text { nywerheid }\end{array} \\ \text { Grondstowwe (1) } & 14.20 & 11.25 \\ \text { Grondstowwe (2) } & 12.75 & 12.95 \\ \text { Elektrisiteit } & 0.33 & 0.65 \\ \text { Arbeid } & 0.73 & 0.90 \\ \text { Ander dienste } & 1.61 & 2.29 \\ \text { Afskrywing } & 1.67 & 2.14 \\ \text { Ander } & 3.23 & 4.14 \\ \text { Vervoerkoste na mark } & - & 4.10 \\ & \underline{\mathrm{R} 34.52} & \mathbf{R 3 8 . 4 2}\end{array}$

Soos $u$ duidelik kon sien, word daar nie gevra wat in 
landsbelang is en of die nywerheidsontwikkeling 'n sekere patroon moet volg nie. Dit was dieselfde argumente wat ons byna ons eerste Yskor, vestiging van 'n tweede Yskor en stigting van Sasol gekos het. Dit is naamlik 'n goue reël dat uitbreidings aan 'n bestaande aanleg altyd goedkoper is as om 'n nuwe een te begin.

Daar was bv. beweer dat die vestiging van 'n derde Yskor R240 miljoen sou kos, terwyl uitbreidings aan die twee bestaande aanlêe om dieselfde kapasiteit te gee, R90 miljoen sou gekos het.

Faktore wat by bostaande kosteberekening ook nie ingesluit is nie, is o.a. verhouding van blanke: bantoearbeid; lugbesoedeling en wat dit sal kos om dit in 'n metropolitaanse gebied teen te werk; afvalwaterbehandeling wat meer akkuraat in die metropolitaanse gebied uitgevoer moet word, en waterverbruik. Hoewel ekonomiese oorwegings belangrik is, is dit m.i. belangriker om te kyk na die landsbelang in die algemeen.

\section{3. 'n Blik in die toekoms.}

Uit die voorgaande is dit duidelik dat toekomstige nywerheidsontwikkeling doelgerig beplan moet word en dat dit verder noodsaaklik is dat die Regering 'n sterk hand hierin sal moet uitoefen, hoewel dit in die praktyk so diplomaties moontlik gedoen behoort te word.

Die klem moet op desentralisasie val, en dit moet die wagwoord wees waarop ons die toekoms bou en dit moet gedoen word langs drie kanale.

1. Desentralisasie om 'n ewerediger verspreiding van kleinere nywerhede op die Suid-Afrikaanse platteland te kry. By die vestiging van hierdie nywerhede moet daar egter gewaak word om alleen die nywerhede in blanke gebiede te desentraliseer wat 'n verhouding van blank tot nie-blank van $1: 1$ handhaaf.

2. Arbeidintensiewe nywerhede moet konsekwent net na een plek gelei word en dit is die grensgebiede.

Pardon, het dit nie nou tyd geword dat ons die term grensgebiednywerhede afskaf en dat ons veel eerder moet dink in terme van nywerhede in die Bantoetuislande nie? Die term grensgebied dui op 'n aktiwiteit op die grens, m.a.w. die inwoners van beide streke is toeskouers van die akti- 
witeit. Met nywerhede in die Bantoetuislande dra ons dan geleidelik die verantwoordelikheid en inisiatief aan hulle oor. Hierdie ontwikkeling is noodsaaklik omdat sommige van die gebiede landboukundig behoeftig is.

3. Die hoofklem moet egter val op die ontwikkeling, uitbouing en vestiging van nywerhede in die Oranjerivierkompleks.

Oor die afgelope drie jaar was die fenomenale groei van die nywerhede in Suid-Afrika so oorweldigend, dat van verskeie kante ernstige pogings aangewend is om wat ek wil bestempel as die tweede na-oorlogse nywerheidsontploffing, se intensiteit te demp deur allerlei teenmaatreëls, ook van regeringskant, in te stel.

Ons kan allerweë aanvaar dat hierdie snelle ontwikkeling stadig maar seker besig is om na die normale terug te keer, en dit het dus weer tyd geword dat die tekenborde uitgestrek word en om planne te begin smee vir nuwe projekte.

Intussen is die ernstige watertekort in die Vaaldriehoek ook voorlopig iets van die verlede en sal die beplanners in die gebied bepaal wat hulle in die toekoms moet doen. Die Vaaldam wat oorloop moet ons egter nie oormoedig maak nie - daarvoor is sy inhoudsvermoë te beperk en die groot eise wat daaraan gestel word te omvangryk.

Dit was nog maar 'n skrale twee jaar gelede dat die Vaaldam oorgeloop het (Jan. 1965), maar die afgelope twaalf maande is daar 'n ongelyke stryd gevoer om voldoende water te voorsien vir die nywerhede en groeiende bevolking ${ }^{3}$ ):

\section{Water verskaf deur Randse Waterraad}

$\begin{array}{ccc}\begin{array}{c}\text { Jaar geëindig } \\ \text { 31 Maart }\end{array} & \begin{array}{c}\text { Miljoene } \\ \text { Gelling/dag }\end{array} & \begin{array}{c}\text { Vermeerdering op } \\ \text { vorige periode } \\ \text { (m.g./d.) }\end{array} \\ 1905 & 2.33 & - \\ 1915 & 9.04 & 6.71 \\ 1925 & 12.2 & 3.16 \\ 1935 & 22.0 & 9.8 \\ 1945 & 66.4 & 44.4 \\ 1955 & 123.5 & 57.1 \\ 1965 & 210.5 & 87.0\end{array}$

Tewens, om in staat te wees om sorgvry vir die toekoms te beplan, sou dit wenslik wees om die opgaarinhoud van 
ten minste twee Vaaldamme tot beskikking te hê of anders 'n konstante aanvulling uit 'n ander bron te bekom.

Die vraag kom egter op of ons nie die potensialiteite en moontlikhede van ons land se ander waterbronne moet benut nie, en dan gaan die gedagte onwillekeurig uit na die Oranjerivierprojek. ${ }^{4}$ ) 'n Paar myl van Norvalspunt is die Verwoerddam tans in aanbou - 'n projek met 'n waterinhoud van etlike Vaaldamme en wat dadelik die aandag trek as een van die moontlike groeipunte in ons land.

Kyk ons na die kaart van bevolkingverspreiding in SuidAfrika, merk ons dadelik dat die Oranjerivierbekken baie dun bevolk is, en dus ook uit hierdie oogpunt en om strategiese redes is dit noodsaaklik dat ons hierdie gebied ontwikkel.

Sommige doemprofete is egter van mening dat min nywerhede na die sentrums sal gaan, omdat dit so ver van die metropolitaanse gebiede en dus van die verbruikersmark is.

Die enigste uitweg wat dus oorbly is dat die Regering met diplomatiese beplanning en 'n ferm hand, nuwe nywerhede na die gebied lei.

Watter nywerhede kwalifiseer hiervoor? M.i. is daar twee wat oorweeg kan word, naamlik:

1. Suid-Afrika se Nasionale Olieraffinadery.

2. Die derde Yskor.

Beide klink belaglike voorstelle, maar ons moet nie uit die oog verloor dat beide ontsaglike groot projekte is nie, wat met hulle omvang en grootte heelwat in hulle skaduwees kan verdra. Kyk maar net wat het die eerste Yskor na Pretoria gebring, en waar sou Vanderbijlpark en omgewing gewees het as die tweede Yskor nie dáár gevestig is nie! Die kritici sal dadelik beweer dat die grootste momentum van die besondere posisie in die Vaaldriehoek gekom het; die feit bly egter staan dat 'n magtige projek soos enige of altwee van bogenoemde heelwat stimulus in 'n nuwe gebied behoort te bring.

Daar word verneem dat die totstandkoming van hierdie twee projekte ' $n$ voldonge feit is, en dat daar tans berekeninge gedoen word, waar die geskikste plek is om hulle te vestig.

Die watertekort wat daar die afgelope tyd in die grotere Vaaldriehoek ondervind is, skakel hierdie gebied as 'n moontlike vestingsoord vir hierdie nywerhede heeltemal uit, en dit behoort glad nie oorweeg te word nie. 
Daar is reeds in een van die aankondigings oor die Nasionale Raffinadery bespiegel dat 'n pyplyn vir die ru-olie aangelê sal moet word. Voor die waterkrisis was die Vaaldriehoek die aangewese plek en sou 'n pyplyn van ongeveer 400 myl nodig gewees het.

Indien die nasionale raffinadery in die omgewing van die Verwoerddam geplaas word, sal 'n pyplyn van ongeveer 220 myl nodig wees om die ru-olie van Oos-Londen daarheen te bring. Hierdie teoretiese punt is ongeveer 220 myl van die aansluitingspunt van die oliepyplyn van Durban via Kroonstad na die Rand, en daar is geen rede waarom die nasionale olieraffinadery se produkte nie by Kroonstad in die pyplyn gestoot kan word nie..$\left.^{5}\right)$

Die vestiging van die raffinadery by die Verwoerddam sou die voordeel hê dat dit die Vrystaatse goudvelde, Bloemfontein, ens. ook kan bedien, en hierdie stap behoort 'n geweldige invloed op die ontwikkeling van die tans onontwikkelde gebied te hê.

Een van die faktore wat moontlik 'n struikelblok mag wees in die vestiging van die derde Yskor in die gebied, is die beskikbaarheid van steenkool.

Ook dit egter behoort nie in die pad te staan nie, omdat dit nou hoog tyd geword het dat steenkool op groot skaal verkooks en verkool (lae-temperatuurse behandeling om net die meer vlugtige stowwe wat rook en mis veroorsaak, af te dryf) behoort te word - die Wet op Lugbesoedeling sal dit vereis. Hierdie hittebehandeling behoort op 'n sentrale of strategiese punt uitgevoer te word - verkieslik in die nabyheid van die steenkoolvelde - die brandbare gas, teer en ander produkte kan dan daar verwerk word terwyl die kooks na die staalnywerheid vervoer word. Ook moet nie uit die oog verloor word nie dat die swaar stookolie uit die olieraffinadery gebruik kan word om kooks te bespaar en om die produksie van die staalnywerheid te verhoog.

Elektrisiteit sal geen probleem in die Oranjevierbekken wees nie, want in die Verslag oor die Projek word aangetoon dat die aanvanklike kragopwekking gelykstaande sal wees aan 8.8 Megawatt by die Verwoerddam en dat dit later tot 41.9 Megawatt sal aangroei.

As o.a. nog 'n legering- of metaalsmeltery wat gebaseer is op elektriese krag, 'n sementbedryf en 'n eenheid om sê seepsoda-chloor te vervaardig, daar gevestig word; het ons 'n 
groot genoeg nukleus om mee te begin en sal ander sekondêre nywerhede spoedig in die groteres se skaduwee volg.

Spoor- en padverbindings lewer ook geen probleme nie, omdat die Oos-Londen-Bloemfontein-spoorlyn feitlik oor die Verwoerddam sal gaan, terwyl die hoofpadroetes ook die gebied deurkruis.

Die Tennessee Valley Authority in die V.S.A. is 'n skema van soortgelyke omvang wat in die depressiejare daar begin is om nuwe lewe in 'n onontwikkelde deel van daardie land te bring. Die slagspreuk van dié skema is: „A River is put to work for the People", en vandag woon ongeveer $4 \frac{1}{2}$ miljoen mense in die vallei.

Die Oranjerivier se naam is die Grootrivier, ek dink ons moet dit in ons nywerheidsontwikkeling op groot skaal inspan.

Om op te som, as ons in Suid-Afrika die ontwikkeling in genoemde drie kanale wil lei, is dit noodsaaklik dat een of ander vorm van stimulus ingestel word. Hier kan die Regering daaraan dink om soortgelyke voorregte as vir die grensgebiede vir algemene desentralisasie in te stel, maar 'n mens wonder soms of die tyd nie ryp genoeg is vir die instelling van 'n arbeids- of indiensnemingsbelasting nie. Hierdie belasting moet daarop gebaseer word dat 'n sekere nywerheid 'n belasting betaal as sy verhouding van Blank: : Bantoe nie inpas by die nasionale patroon nie; gebruik 'n nywerheid bv. 'n groot aantal Bantoes in blanke gebied, word 'n spesiale belasting gehef om hom te ontmoedig om daar te vestig of om hom te forseer om sy produksie-eenhede kapitaalintensief te maak. Die geld wat so geîn word, kan dan direk gebruik word vir nywerheidsontwikkeling in die Bantoetuislande.

Oor die afgelope aantal jare het ons breed gespekuleer om die moontlikhede en vordering van ",selfstandige” ontwikkeling en die verwydering van Bantoes uit die blanke gebiede. Syfers en statistieke toon egter dat die saak eerder versleg as verbeter, en elkeen van ons hoop en vertrou dat die volgende geslag die probleem sal oplos. Dit is nou egter die tyd om die probleem finaal, sistematies en doelgerig aan te pak en in die praktyk deur te voer - anders erf ons nageslag steeds meer en meer ' $n$ moeilike probleem.

$\mathrm{Na}$ my mening moet ons inderdaad beplan om teen 1980 'n bevolking van tussen 25,000 en 50,000 in die Oranjeriverbekken te vestig, en die van ons wat so liries kan raak oor die voortreflike eienskappe van die gebied, droom al klaar 
dat 'n K.U. eendag in die verre toekoms daar gevestig gaan word - ek profeteer natuurlik nou van die Karoo Universiteit. P.U. vir C.H.O.

S. P. Ligthelm.

1. Hansard, Deel 8, bladsy 1042, 1927.

Norval, Dr. A. J.: Twenty-five Years of Industrial Development in South Africa.

2. Die Transvaler, bladsy 6, 1966.

3. Randse Waterraad, Pamflet: 'n Toenemende Aanvraag, 1966.

4. Verslag oor die Voorgestelde Oranjerivierontwikkelingsprojek, Sekretaris van Waterwese, 1962/63.

5. Annual Report, S.A.R. \& H., 1963/64, R.P. 52/64. 